\title{
Editors' Speak
}

\section{Readers' Special}

This issue is dedicated to the various articles submitted by our readers. We have been constantly trying to conjure topic-based issues, but the increasingly overwhelming response from our readers often compels us to compile issues which contain excellent articles submitted by them, but may not adhere to a specific topic in totality.

Again, and ever so happily, this is by you all, and for you all!

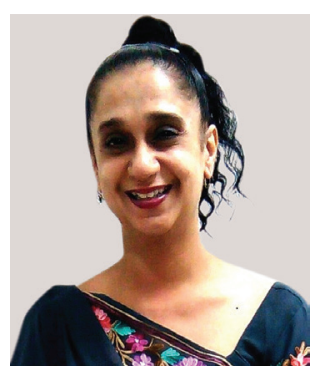

Bachi T Hathiram

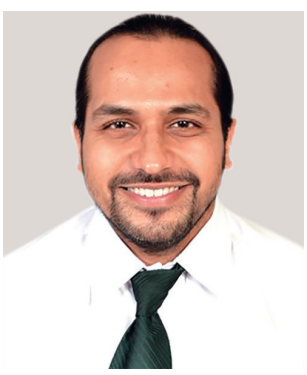

Vicky S Khattar

Editors-in-Chief

Bachi T Hathiram Professor and Head

Department of ENT and Head and Neck Surgery

Topiwala National Medical College and BYL Nair Charitable Hospital, Mumbai, Maharashtra, India

Visiting Consultant

Sir HN Reliance Foundation Hospital and Medical Research Center, Mumbai, Maharashtra, India

Vicky S Khattar Assistant Professor

Department of ENT and Head and Neck Surgery

Topiwala National Medical College and BYL Nair Charitable Hospital, Mumbai, Maharashtra, India

Visiting Consultant

Sir HN Reliance Foundation Hospital and Medical Research Center, Mumbai, Maharashtra, India 